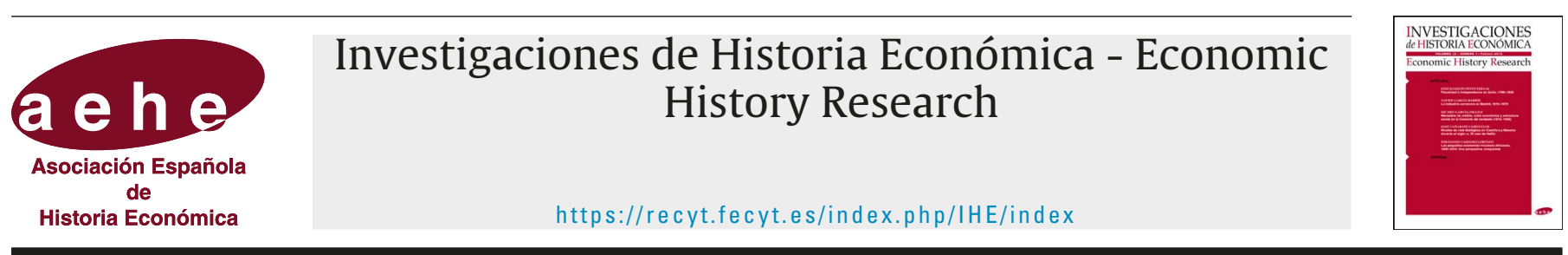

Artículo

\title{
La reconversión en la industria de equipos de telecomunicación entre finales de la década de 1980 e inicios del siglo XXI . El caso de Alcatel-SESA
}

\section{Ángel Calvo*}

Universitat de Barcelona, Facultat d'Economia i Empresa

\section{INFORMACIÓN DEL ARTÍCULO}

\section{Historia del artículo:}

Recibido el 23 de febrero de 2018

Aceptado el 27 de agosto de 2018

On-line el 4 de febrero de 2020

\section{Códigos JEL:}

NO

N1

N6

03

F2

Palabras clave:

Alcaltel

Standard Eléctrica

Industria de equipos de telecomunicación

Reconversión

Oligopolios

Crisis industrial

\section{JEL classification:}

NO

N1

N6

03

F2

Keywords:

Alcatel

Standard Eléctrica

Telecommunication equipment industry

Reconversion

Oligopolies

Industrial crisis

\section{R E S U M E N}

Los avances tecnológicos provocados por la microelectrónica, la informática y la fibra óptica despejaron el camino a la poderosa ola mundial de desregulación de las telecomunicaciones en la última década del siglo xx. A su vez, activaron profundas transformaciones en la industria de equipos de telecomunicaciones. El vínculo tradicional entre operadores y productores de equipos se rompió y la integración vertical entre el servicio y la industria se fragmentó. Como consecuencia, incluso cuando el mercado del sector seguía siendo oligopólico, se requería una reestructuración. El artículo examina la trayectoria de reconversión en la mencionada industria española durante la segunda mitad de la década de 1980 y los inicios del siglo xxı. Analiza la compleja interacción entre múltiples actores en la configuración de la nueva industria global en el entorno de la creciente integración de España a la economía mundial, de la división internacional del trabajo y del aumento de la competencia internacional.

@ 2018 Asociación Española de Historia Económica.

\section{The reconversion in the telecommunication equipment industry between the late 1980s and the beginning of the 21st century. The case of Alcatel-SESA}

\author{
A B S T R A C T
}

The technological developments brought about by microelectronics, computer science and fiber optics paved the way for the powerful global wave of deregulation of telecommunications in the last decade of the 20th century. In turn, they activated profound transformations in the telecommunications equipment industry. The traditional link between operators and equipment producers broke down and the vertical integration between the service and the industry was fragmented. As a consequence, even when the market of the sector remained oligopolistic, restructuring was required. This article examines the reconversion in the aforementioned industry in Spain between the end of the 1980s and the beginning of the 21st century. It analyzes the complex interaction between multiple actors in the shaping of the new global industry within the increasing integration of Spain to the world economy, the international division of labor and the intensification of international competition.

@ 2018 Asociación Española de Historia Económica.

\footnotetext{
* Autor para correspondencia.

Correo electrónico: angel.calvo@ub.edu (Ángel Calvo)
} 


\section{Introducción}

Al decir de organismos internacionales solventes, las telecomunicaciones, en sus variantes de industria y servicio, son el área más crítica para influir en el "sistema nervioso» de la sociedad moderna ${ }^{1}$. Centrado en la primera vertiente, este artículo parte de las diferencias nacionales en la recomposición del oligopolio mundial de la industria de equipos de telecomunicación (el sector en estudio o el sector) para abordar el papel desempeñado por España en ese proceso como país del sur de Europa, neófito en la CEE. En su condición de Estado nacional de economía no central, España tenía un modelo de producción de baja tecnología y no competitivo, excesivamente ligado a componentes de crecimiento inestables, mano de obra barata, modestas contribuciones de capital y baja productividad total de los factores. En el cuarto final del siglo xx, la industria redujo su participación en el producto real total de la economía española, una tendencia común a los países industriales. Con todo, elevaron su participación las ramas de demanda y nivel tecnológico medio y alto, entre estas últimas la maquinaria eléctrica y electrónica principalmente $^{2}$. Sin duda, un factor diferencial que añade atractivos al caso de España es la prolongación temporal del monopolio de una compañía mixta que ostentaba la Compañía Telefónica Nacional de España (CTNE), principal cliente de equipos, a diferencia de una Europa que liberalizaba sus operadoras públicas, calificadas de mastodontes o dinosaurios. La CTNE, pronto rebautizada como Telefónica, liquidaba su holding industrial para iniciar una expansión internacional inusitada como operadora de redes, convirtiendo a los países en que se implantaba en un mercado potencial para las empresas españolas. Por su parte, cuatro años después de que la Comisión Europea liberalizase el mercado de terminales de telecomunicaciones, en España una modificación de la Ley de Ordenación de las Telecomunicaciones (LOT) de 1992 despejó el camino a dicha liberalización ${ }^{3}$.

El texto sigue el esquema de Olley y Pakes (1996, pp. 12631297), según el cual el cambio tecnológico y la desregulación provocaron una importante reestructuración del sector en estudio, con cambios significativos en el tamaño y número de empresas previamente establecidas. Al mismo tiempo, se inserta en un marco teórico que reconoce las discrepancias en los procesos de reconversión dentro de la globalización de la economía y el papel destacado de las empresas multinacionales ${ }^{4}$.

Por su contenido, el artículo aspira a colmar una laguna en la narrativa histórica, volcada en los grandes hitos de la reconversión industrial en España (especialmente en las industrias

\footnotetext{
${ }^{1}$ Commission of the European Communities (1987, p. 1).

2 Becattini et al. (2009, p. 343); Kaldor et al. (2015, p. 120); Rojo (2002, pp. 397-436).

3 Calzada y Costas (2016, pp. 165 y 167). A título de ejemplo, las ventas de Amper en el mercado exterior representaban un $23 \%$ de la facturación total, suma del 12,2\% de Telefónica en el exterior y del 10,8\% de otros operadores internacionales: Amper (2000a, p. 29).

${ }^{4}$ Kornelakis (2015, pp. 885-902); Ruigrok y van Tulder (1995); Fitzgerald (2015, p. 440). Conecta asimismo con los debates de los años 1980 en torno a la relación entre Gobiernos nacionales y empresas multinacionales (Poynter, 2013). Según una de las bases teóricas escogidas, el deslizamiento de la inversión hacia establecimientos más productivos habría actuado de palanca de las transformaciones (Olley y Pakes, 1996, p. 1269).
}

siderúrgica y naval) $)^{5}$. Apuesta por imitar a los expertos en otros sectores y llevar al terreno de la historia económica episodios cruciales de la reconversión de las industrias de tecnología avanzada en España ${ }^{6}$. Uno de ellos corresponde a la reconversión de Alcatel-Standard Eléctrica (Alcatel-SESA), heredera de la histórica Standard Eléctrica, fabricante de equipos de telecomunicación desde su creación por IT\&T, y filial de la francesa Alcatel N. V. tras la desinversión de la multinacional norteamericana 7 . De carácter preciso si bien restrictivo, el presente estudio deja fuera de su ámbito las antiguas filiales españolas de IT\&T -Marconi Española y CITESA-, así como el antiguo holding industrial de Telefónica y la división electrónica e informática del INI, merecedores de estudios específicos, actualmente en elaboración.

El sector presenta un caso histórico que considerar debido a la creciente inserción de España, país no central como queda dicho, en el mercado mundial y a su condición reciente de miembro del mercado único europeo. Abordar la evolución de la multinacional Alcatel N. V. en España proporciona elementos sustanciales a la comprensión de la muy compleja evolución de la industria española en el corte cronológico comprendido entre finales de la década de 1980 y los años iniciales del nuevo milenio. El periodo abarca diversas transiciones determinantes, desde la incorporación de España a la UE y la propia liberalización de las telecomunicaciones hasta la globalización de la economía, sin olvidar el desplazamiento de las políticas socialdemócratas por las neoliberales en Europa.

El texto se organiza en cuatro secciones principales, que trazan la encrucijada del sector a nivel internacional antes de pasar a examinar sucesivamente la política industrial dentro de la situación del sector en España, la reanudación de la reconversión a partir de la década de 1990 y el papel de Alcatel-SESA en la imposición de la estrategia fab-less de la casa madre. Desde el punto de vista metodológico, el artículo plantea una pauta que hace intervenir conjuntamente múltiples

\footnotetext{
${ }^{5}$ Subrayamos ese carácter especial, y por tanto no exclusivo, de la atención prestada a los grandes hitos de la reconversión industrial en España; valga como ejemplo el subsector de los electrodomésticos de línea blanca estudiado desde el caso de Fagor por De la Torre (2017, pp. 26-37) y representado por otras tres empresas vascas: Bergara, Ulgor y Fabrelec.

${ }^{6}$ El sector de las TIC (Tecnologías de la Información y la Comunicación) en España sí ha recibido atención con un enfoque interdisciplinar por parte de un restringido grupo de estudiosos, entre los que destacan López (2016, pp. 159-180); López y Molero (2005); López, Pueyo y Zlatanova (2002, 8196); López (2016, pp. 159-180). Valgan varias aportaciones centrales de historiadores económicos sobre España, sin pretensiones de exhaustividad: Díaz-Morlán y Sáez-García (2017, pp. 38-50); Díaz Morlán y Sáez García (2017a); Díaz-Morlán (2009, pp. 547-568); Díaz Morlán et al. (2008, pp. 161-188); Valdaliso (2003, pp. 52-67); Fernández de Pinedo (2003, pp. 28 51); Navarro (2005, pp. 167-184; 1989); dos referencias generales muy significativas: Velasco y Plaza (2003, pp. 155-180); Buesa y Molero (1988 pp. 1-28); un estudio sobre acuerdos salariales concretos: Sagardoy (1984, pp. 33-77). Para aproximaciones desde las políticas mundiales de telecomunicaciones, véase Amesse et al. (2004, pp. 885-897) y Neu et al. (1987, pp. 31-44).

${ }^{7}$ La adquisición de las filiales europeas de IT\&T por CGE fue llamada el "acuerdo del siglo» (Owen, 2012, p. 29). Como sucesora de IT\&T, Alcatel presentaba un perfil de multinacional con dilatada presencia industrial en España, contrapuesto, por tanto, al de otros dos tipos de multinacionales -sin actividad industrial, aunque con ventas en el país, y sin apenas presencia alguna en el mercado español (intervención de P. M. García, director de Actualidad Electrónica, Congreso de los Diputados, 24-10-1984 229, p. 7201).
} 
agentes y utiliza fuentes de naturaleza y procedencia diversas, entre las que destacan las primarias, tanto de carácter público como privado, combinación indispensable en un contexto de no excesiva abundancia de documentación ${ }^{8}$.

\section{La industria mundial de equipo de telecomunicación en la encrucijada}

El gigantesco y veloz cambio tecnológico causado por la conmutación digital, la microelectrónica y la transmisión de fibra óptica erosionó el «monopolio natural» de las telecomunicaciones e impulsó la privatización y la liberalización en la última década del siglo xx. De este cambio se derivaron profundas transformaciones en la industria de equipos de telecomunicación. En Estados Unidos, el desmembramiento de AT\&T en empresas de ámbito regional, las llamadas baby Bells, y la desintegración vertical de su brazo manufacturero Western Electric socavaron la estabilidad del mercado al diversificar los proveedores. El vínculo tradicional entre operadoras y productores de equipos se rompió y la integración vertical entre servicio e industria se fragmentó. El mercado regional del sector siguió siendo oligopólico, pero requería una reestructuración de índole transnacional ${ }^{9}$.

A partir de mediados de la década de 1980, se inició una carrera competitiva para ocupar los huecos abiertos por algunas compañías en su apuesta por los grandes conglomerados de empresas, como sucedió con IT\&T, matriz histórica de SESA. En definitiva, se quebró la antigua división internacional del trabajo basada en el reparto del mundo entre los dos gigantes estadounidenses. AT\&T dejó de centrarse en el mercado interior para convertirse en un competidor mundial e IT\&T buscó una tremenda diversificación de áreas de negocio y desinvirtió de su división industrial.

En Europa, la nueva división internacional del trabajo empujó a las empresas a priorizar las telecomunicaciones, mientras que las japonesas se inclinaban por otros ámbitos, como el procesamiento de datos o la electrónica audiovisual $^{10}$. La evolución de la industria de las telecomunicaciones tendió a ser condicionada por la creciente demanda de nuevos y mejores servicios ${ }^{11}$. Entre 1989 y 1995, los datos y los teléfonos móviles duplicaban con holgura el crecimien-

\footnotetext{
${ }^{8}$ En lo relativo a múltiples agentes, sigue a especialistas de otros sectores industriales, entre ellos Díaz Morlán et al. (2008, p. 184) y Viaña (1991). Entre las fuentes primarias, destacan las de procedencia parlamentaria Congreso de los Diputados y organismos autonómicos-, así como las de la Comisión de las Comunidades Europeas, consultadas online. Revisten extraordinario interés, entre las secundarias, los informes de la propia empresa y la serie de Informe sobre la Industria del Ministerio de Industria y Energía. En esa no abundancia de datos que nos asola, la hemeroteca cobra especial relieve. Si bien su información debe ser sometida a obligatorio contraste por posibles sesgos, contiene detalles importantes, procedentes directamente de los distintos agentes o de órganos próximos a los centros de decisión.

${ }^{9}$ European Commission (1997, p. 39); Crandall y Flamm (1989); Feldstein (2007, p. 420); Moreau (2009, p. 176); Forester (1987, p. 88). Las formulaciones de esa gran transformación de los negocios y la sociedad en todo el mundo varían sin afectar al fondo de los hechos (Stone, 1989, p. 90). La competitividad del sector en estudio depende fuertemente de la disponibilidad de componentes electrónicos, usados también para el software (Commission of the European Communities, 1992, p. 5).

${ }^{10}$ Schmoch y Schnöring (1994, pp. 397-413).

11 Brown (1994, p. 3).
}

to de la conmutación y los terminales de telefonía fija. Con todo, la supremacía de los servicios de voz en la telefonía, ante el empuje arrollador del teléfono móvil, resultaba incuestionable ${ }^{12}$.

En un entorno regulador cambiante y pese a los desafíos comunes planteados por la integración del mercado y la liberalización, el comportamiento de las operadoras europeas de telecomunicaciones sugiere una variedad de pautas de ajuste y vías de privatización. En ese contexto de transición al mercado único europeo y de aumento de la competencia internacional, fueron las políticas industriales y tecnológicas aplicadas en los Estados nacionales las que avivaron contrastes en la configuración de la industria.

Antes de proseguir, valgan unas consideraciones preliminares. La más genérica integra el concepto de conversión y reestructuración -reajustes organizativos y laborales internos, fusiones, compras y empresas conjuntas-, a la vez que define como compleja la naturaleza de la reestructuración institucional y técnica en las telecomunicaciones ${ }^{13}$.

En cuanto a aspectos más específicos, las TIC se presentan como eje de las estructuras productivas de las sociedades industriales avanzadas, responsables de una tasa de crecimiento superior al nivel general de la industria manufacturera ${ }^{14}$. Parece importante subrayar los rasgos más sobresalientes de la industria de equipos de telecomunicación, empezando por su carácter estratégico y de general purpose technology con efectos sobre la totalidad del sistema económico, que incita a una postura intervencionista del Estado, como agente de la política industrial, según el modelo latino de gobierno corporativo ya fuertemente erosionado, y fuente de financiación de la I+D. El sector en estudio se compone de tres tipos principales de productos: equipos de conmutación, de transmisión y aparatos de abonado o terminales ${ }^{15}$. Su estructura de costes arrojaba el predominio palmario de los materiales tanto en el equipo de conmutación como en los terminales telefónicos, traducido en una intensidad tecnológica y de capital. En la fabricación del uno y de los otros existían economías de escala a corto plazo ${ }^{16}$.

Varios rasgos completaban las características de esa industria: su acentuada exposición a los impactos de las innovaciones tecnológicas y la consiguiente rápida obsolescencia de los

\footnotetext{
${ }^{12}$ European Communities (1992). Al final de la década de 1980 los servicios de voz representaban alrededor del $90 \%$ de los ingresos de las operadoras (Council of Europe, 1990, p. 15).

${ }^{13}$ Mansell et al. (1990, pp. 51-66); la Comisión Europea (1991) restringía el concepto de reestructuración a fusiones y empresas conjuntas. Para el caso de España, algunos autores atribuyen a la actividad legislativa de 1983-1984 sobre reconversión y reindustrialización como objetivo central el reajuste de especializaciones productivas y la remodelación de activos (Velasco y Plaza, 2003, p. 159).

14 Bit, julio-agosto de 1981, pp. 10-11. En 1990, el mercado comunitario de las telecomunicaciones se cifraba en 116 mil millones de ECU, suma a la que los servicios aportaban el $77,58 \%$ y los equipos el $22,41 \%$ restante (Commission of the European Communities, 1992, p. 5).

${ }^{15}$ Arpege Group (1994, p. 2). Modelo latino de gobierno corporativo, caracterizado por el papel central del Estado y los holdings, recientemente desgastado por la privatización y el aumento de las inversiones de las instituciones financieras, especialmente las extranjeras (EurWORK, 2003). ${ }^{16}$ WS Atkins Management Consultants (1988, pp. 149 y 156). Con la introducción de la electrónica los costes salariales unitarios del equipo de conmutación se redujeron a menos de la mitad y el trabajo necesario hasta la tercera y cuarta parte (Doz, 1979, pp. 82-84).
} 
productos, junto con las altas barreras de entrada y el papel crucial desempeñado por el tamaño entre las empresas competidoras debido a la demanda cíclica ${ }^{17}$.

En lo tocante a la estructura de mercado, y refiriéndonos más a Europa, asistimos al final de los monopolios estatales o PTT, que se abastecían de equipos de telecomunicación de un restringido grupo de fabricantes nacionales ${ }^{18}$. En ausencia aún de normas supranacionales, estos ajustaban sus productos a cánones nacionales y, por tanto, erigían una «barrera no arancelaria» a la entrada de empresas extranjeras, poco proclives a ingentes inversiones sin garantía de lograr cuotas de mercado suficientes para resarcirse de los elevados gastos de desarrollo ${ }^{19}$.

A propósito de la distribución geográfica, la producción y el consumo mundiales de equipos de telecomunicaciones se concentraban en siete países desarrollados, encabezados por Japón y EE. UU. (y sus empresas multinacionales) ${ }^{20}$. En el sector la concentración continuó a lo largo de la década de 1990. A mediados de la misma, las diez empresas más importantes de EE. UU., Europa y Japón sumaban más del 60 $\%$ del mercado mundial ${ }^{21}$. Lejos de detenerse, la reorganización de la estructura oligopólica del sector continuó en los años siguientes, si bien sobrevinieron cambios importantes en las estrategias de cooperación, explicables por la dinámica de la demanda y las tecnologías en diferentes sectores del mercado.

Movimiento en profundidad, el excepcional dinamismo de las TIC dejó de correr parejo con un crecimiento en valor. Las operadoras del servicio se vieron forzadas a ajustar sus compras de forma muy estricta, lo que afectaba negativamente a los fabricantes de equipos. Este bajo crecimiento en valor condujo a la progresiva consolidación entre operadoras, principales clientes de los industriales, y de sus subcontratistas,

\footnotetext{
17 Thatcher (1999, p. 58). El ciclo de vida de la tecnología digital acortaba unos dos decenios el de la electromecánica (Hendry y Eccles, 2005, p. 135); para la industria de alta tecnología, véase Patrick (1986, pp. 6-8).

18 WS Atkins Management Consultants (1988, p. 139).

19 Thatcher (1999, p. 58). Las empresas requieren fortaleza financiera para que la rápida innovación pueda soportar una intensa competencia en un entorno de fuertes caídas y esfuerzos para recibir subsidios del Estado (Baskoy, 2008, p. 148). El elevadísimo coste de desarrollo de una nueva familia de conmutadores de división de tiempo -entre 700 y 1300 millones de dólares- chocaba con la enorme cuantía de las ventas necesarias para lograr un rendimiento razonable de los costes de desarrollo -14000 millones de dólares- y lo exiguo del tamaño de los mercados nacionales -7200 millones el británico, 10900 el francés y 11700 el alemán(Commission of the European Communities, 1983, p. 36).

${ }^{20}$ En 1990, la producción mundial de equipos de comunicación aumentó a 64000 millones de dólares, desde casi 38000 millones siete años antes (Butcher, 1991, pp. 2-11).

${ }^{21}$ El grupo incluía AT\&T-Lucent, Motorola, Siemens, Alcatel Alsthom, Ericsson, NEC, Nortel, Nokia, Fujitsu y Bosch (Dörrenbächer, 2000, p. 13); en 1997, Alcatel tenía el $4 \%$ de la infraestructura mundial de telefonía móvil y el 2,5\% de terminales, cifra que dos años después había subido al $4,2 \%$, siempre a la zaga de los grandes del sector -Nokia, Motorola y Ericsson- (Funk, 2002, p. 8). En la industria europea, la ratio de concentración o cuota de mercado de las cuatro principales empresas mostró comportamientos discrepantes según países y sectores: en el conjunto de Europa, aumentó en 2,3 puntos porcentuales entre 1987 y 1993, mientras que en Francia, el Reino Unido y Bélgica disminuyó. A su vez, en las telecomunicaciones, junto a otros sectores relacionados con la contratación pública, aumentó la concentración de la industria en más del $5 \%$ (Johnson y Turner, 2005, p. 51). Sobre fusiones y adquisiciones véase
} Amesse et al. (2004, pp. 885-897). que a su vez se vieron arrastrados a nuevas reestructuraciones, especialmente bajo la forma de fusiones y adquisicio$n^{22}$. En el cambio de década, el estallido de la burbuja punto.com que siguió al derroche en las compras de licencias de telefonía móvil propinó un golpe mortal al sector y, en definitiva, al crecimiento económico con efectos negativos sobre el empleo ${ }^{23}$.

\section{La política industrial y el sector en España: el medio plazo}

Trazado el marco internacional, parece pertinente una breve referencia a la situación del sector retrocediendo en el tiempo. Como se ha apuntado más arriba, en la primera mitad de la década de 1980 la industria de equipos de redes estaba integrada en España por las tres filiales de IT\&T -SESA, Marconi Española y CITESA-, el holding industrial de la CTNE -Amper, Telettra e Intelsa (Industrias de Telecomunicación S. A.), entre otras- y, como representante del capital público, la recién creada división electrónica e informática del Instituto Nacional de Industria (INI). En el grupo de empresas de IT\&T, de larga implantación en España, SESA, una de las joyas de la corona, cubría el suministro de equipos de conmutación y de cables en sus fábricas de Madrid y la localidad cántabra de Maliaño, respectivamente. Pese a una primera «liberalización» en el suministro de equipos en los años sesenta, una parte sustancial de los ingresos de SESA procedían de su cliente privilegiado, la CTNE, que, además, tenía una participación minoritaria pero significativa en la empresa. El holding industrial de Telefónica fue formado por la operadora para asegurarse segundos proveedores en equipos de conmutación y transmisión. A las históricas, ya citadas con anterioridad, se añadió un racimo de empresas impulsadas por la CTNE durante la etapa de Luis Solana, en una actuación asimilable a la de un segundo ministerio de Industria, aprovechando su capacidad de compra y la disponibilidad de recursos financieros independientes de los presupuestos generales del Estado, bien es cierto, condicionados por la política tarifaria, a su vez tutelada por el Gobierno ${ }^{24}$.

En el conjunto de la industria española, la crisis, que arrancó en 1974, acarreó una progresiva descapitalización y un elevadísimo endeudamiento de las empresas, origen de elevados costes financieros.

\footnotetext{
22 Loos y Larcher (2007).

${ }^{23}$ Ericsson anunció la supresión de 20000 puestos de trabajo para 2003 y Siemens, 6500; Lucent y Nortel pronto verían sus plantillas reducidas drásticamente. Un fenómeno clásico de desaceleración de la demanda en un mercado maduro se combinó con una retroalimentación desproporcionada de la economía financiera a la economía real (Laffitte y Trégouët, 2001). El desplome de la industria de telecomunicaciones provocó aproximadamente la cuarta parte de la disminución del crecimiento económico entre la primera mitad de 2000 y la primera mitad de 2001 (Brenner, 2003, p. 295)

${ }^{24}$ Telettra España e Intelsa, empresas conjuntas con la multinacional italiana Telettra y con Ericsson como socios tecnológicos, fabricaban equipos de transmisión y de conmutación, respectivamente. El aumento del $9 \%$ en las tarifas propuesto por la CTNE en 1984 fue vetado por la Administración, que retuvo un tiempo el plan cuatrienal de inversiones de la compañía operadora. Las empresas señalaron los riesgos para la industria electrónica y para los primeros acuerdos suscritos entre el ministerio de Industria e IT\&T sobre la reestructuración de SESA (El País, 3-1-1984; Calvo, 2016, p. 245).
} 
La intervención estatal se hizo esperar por más que se reconociera la urgencia de la situación. La política industrial auspiciada por el gobierno cuajó en los primeros años ochenta en un cuerpo normativo primordial. En conjunto, se centró en la reconversión industrial con el objetivo de conseguir empresas listas para competir en mercados abiertos ${ }^{25}$. A dos de las filiales de IT\&T en España -SESA y Marconi Española- les acompañaron en la reconversión industrial numerosas empresas de otros diez sectores estratégicos o básicos, pertenecientes a la industria pesada y ligera. Se trataba de los siguientes: construcción naval, siderurgia integral, aceros especiales, electrodomésticos de línea blanca, textil, fertilizantes, componentes electrónicos -factor importante de la competitividad de la industria de equipos de telecomunicaciones-, equipo eléctrico de automoción, semitransformados del cobre y forja pesada por estampación. A ellos se añadía el Grupo ERT (Explosivos Río Tinto), que acumulaba una deuda bancaria de 125.000 millones de pesetas ${ }^{26}$.

Desde finales de la década de los setenta, SESA venía arrastrando problemas derivados de la crisis de demanda y de la obsolescencia de sus productos, vinculados a la conmutación electromecánica cuando se imponía la electrónica. Veamos el perfil de la empresa a comienzos de los años ochenta para calibrar mejor su peso en la reconversión general. Empezando por el tamaño relativo y con la facturación como referencia, quedaba muy lejos del volumen de los gigantes de la construcción naval (36,31\%), del textil (12,19\%), del grupo ERT (15\%), de la siderurgia integral (19,08\%) y de los fertilizantes (37,46 \%). La empresa se situaba a medio camino de los electrodomésticos de línea blanca $(53,45 \%)$ y se acercaba a los aceros especiales (92,50 \%). Finalmente, por facturación superaba con holgura a otros representantes del sector de las TICs (a Marconi Española con el 485,79 y a los componentes electrónicos con el 393,41 \%), multiplicaba por 1,6 la del equipo eléctrico de automoción, casi cuadruplicaba la de los semitransformados del cobre y octuplicaba con creces la de la forja pesada por estampación. Por los mismos años, los costes de personal, medidos en porcentajes sobre las ventas, presentaban a SESA como una empresa intensiva en mano de obra. Siempre considerando los sectores en reconversión, los costes de personal se situaban entre los dos más altos ya que solo eran superados por los semitransformados del cobre. Marconi Española y los componentes electrónicos quedaban

\footnotetext{
25 RD 876/1981, de 8 de mayo, sobre Medidas de Reconversión de la Siderurgia Integral, BOE, 120, 20-5-1981, pp. 10824-10826; RD 2010/1981, de 3 de agosto, sobre Medidas de Reconversión del Sector Textil, BOE, 217, 10-9-1981, pp. 20843-20846. Si nos atenemos a la siderurgia integral como ejemplo, concentrada en tres grandes empresas -Ensidesa, AHV y AHM-, el desplome de la demanda interior y de la productividad e incremento de los costes, especialmente de los enérgicos y de personal, sumaron sus efectos perniciosos hasta provocar una profunda crisis de alcance mundial. A la reconversión industrial de componentes electrónicos se incorporaron dos empresas, Bianchi, S.A. y Fagor Electrotécnica, junto al grupo Piher, formado por Piher, S. A., Piher Navarra y Piher Ferritas, con plantas en Badalona y Tudela (RD 769/1982, de 26 de marzo, BOE, 289, 2-12-1982, p. 33283); más tarde se sumaron Premo, Inysa, Cía. de Componentes Electrónicos, Componentes Electrónicos S. A., TECOSA y Oriega Ibérica (Ministerio de Industria y Energía, 1983, p. 171).

26 El Ministerio de Industria y Energía (1987, passim); El País, 21-4-1983, y Buesa y Molero (1988, p. 11bis) presentan, en síntesis apretada, las características esenciales de las políticas de reconversión. ERT soportaba intereses mensuales de unos 1700 millones de pesetas.
}

19,4 y 23,1 puntos porcentuales por debajo. Pese a la presunta importancia de la cualificación de la mano de obra, SESA no salía muy favorecida por su productividad comparada dentro de los sectores en reconversión. Le acompañaban en tan poco boyante posición el resto de las TIC, y tan solo superaba a los semitransformados del cobre. La inversión presentaba asimismo porcentajes modestos respecto al conjunto de sectores en reconversión. SESA se distinguía, en contrapartida, por sus bajos costes financieros con una posición situada entre los del textil y aceros especiales, por debajo, y fertilizantes, ligeramente por encima. El 8,8 \% de inversión sobre las ventas de SESA distaba mucho del $34 \%$ de los semitransformados del cobre, pero también del 17,9 \% de la siderurgia integral y del Grupo ERT. Su posición era sensiblemente mejor que la de los componentes electrónicos y la de Marconi Española ${ }^{27}$.

En el sector que nos ocupa, el Gobierno entendió que las inversiones en infraestructuras necesarias para garantizar un servicio telefónico adecuado habían generado un crecimiento acelerado de la demanda interior de productos de telecomunicaciones. Fruto de ese comportamiento era la saturación de la capacidad de producción de la industria instalada en España $\mathrm{y}$, por ende, un crecimiento significativo de las importaciones. El carácter temporal del esfuerzo de la industria española para satisfacer la demanda pujante parecía desaconsejar el sobredimensionamiento de la base industrial, que reforzaría la vulnerabilidad al caer la demanda.

La política del Gobierno se plasmaba, pues, en diversas actuaciones de carácter normativo y propiamente industrial. Nos referimos a la adaptación a las directrices comunitarias -centradas en la desregulación y el logro inmediato de un mercado único- ${ }^{28}$ y al fomento de una industria nacional de telecomunicaciones basada en la capacidad de compra de las Administraciones públicas y de Telefónica. En 1989, el objetivo de conseguir una adecuada dimensión y un potencial tecnológico para competir en Europa llevó a crear en torno a Amper un grupo de comunicaciones civiles y militares con capital español. El Gobierno impulsaba, a su vez, el Plan Electrónico e Informático Nacional (PEIN), sustancialmente un programa de subvenciones al desarrollo tecnológico de las empresas $^{29}$.

\footnotetext{
27 Ministerio de Industria y Energía (1987, p. 117).

${ }^{28}$ El corte cronológico escogido aquí coincide con la llamada segunda fase de las políticas industriales comunitarias europeas, de carácter horizontal o no selectivo, destinadas a mejorar el clima de negocios para todas las empresas y que ponía un mayor énfasis en la competencia (Owen, 2012, p. 3). A petición de los Estados miembros implicados, se activaban instrumentos comunitarios, como el Fondo Europeo de Adaptación a la Globalización (FEAG), cuando los despidos atañían directamente a los efectos de la globalización, y el Fondo Social Europeo (FSE).

${ }^{29}$ Luis Solana Madariaga, conversación con el autor, Madrid, 8-3-2016; comparecencia de don Joan Majó Cruzate, director general de Electrónica e Informática, en relación con el Plan Electrónico e Informático Nacional (Diario de Sesiones del Congreso de los Diputados, 213, 9-10-1984, pp. 64646465); European Commission (1991). España ostentaba uno de los niveles más bajos de no inserción de la normativa del Single European Market en su legislación (Johnson y Turner, 2005, p. 57). El PEIN III para el periodo 19911993 concedía un lugar destacado a las telecomunicaciones. El Gobierno se fiaba de las promesas por las que Telefónica pretendía situar los pedidos de equipos en el nivel más elevado posible, siempre dentro del respeto a las vigentes legislaciones española y comunitaria (Congreso de los Diputados, contestación del Gobierno, 12-9-1990, pp. 265-266). Amper Radio, fundada en 1956 por el ingeniero Antonio Peral para fabricar porteros automáticos, se
} 
La reconversión industrial impulsada por los Gobiernos europeos y, en concreto, por el español junto a algunos autonómicos, entrañaba el uso de cuantiosos recursos públicos. Resulta innegable que una parte de la reconversión de Alcatel-SESA recayó sobre las arcas públicas y que el Ejecutivo asumió funciones de mediación e impulso de la negociación, actitud compartida por otras entidades públicas. La aportación pública se concentró en los años finales de la década de 1980, con un marcado retraso respecto a la intervención normativa. A la hora de las comparaciones pertinentes, los recursos públicos empleados en Alcatel-SESA no alcanzaron ni de lejos la relevancia de la inversión privada realizada en el mismo sector ni de la inversión pública en otros sectores ${ }^{30}$. En cualquier caso, ese nivel de gasto público empleado en la reconversión no fue a gusto de todos. Ante la mayor acritud de los efectos de la reconversión en España, la oposición parlamentaria censuró la tibieza de las autoridades españolas ante la reconversión de 1996 y la connivencia con la empresa, pormenor sobre el que volveremos más adelante ${ }^{31}$. Conviene señalar que esta última fecha nos pone ante un cambio de ciclo político que marca la transición de las políticas socialdemócratas al neoliberalismo económico propio de la derecha, con reducciones de impuestos, del gasto público y del intervencionismo de las Administraciones públicas en la economía ${ }^{32}$.

convirtió en proveedora de equipos de la CTNE, que acabó comprándola en 1982 y a finales de la década la utilizó para afianzar sus posiciones en acuerdos internacionales, creando con Motorola la empresa Telcel (Calvo, 2014, p. 242). A finales de 1990, el grupo Amper, enfrentado al reto de la competencia y exigencias del mercado, se reestructuró según el esquema de unidades especializadas por productos -telefonía pública, telefonía inalámbrica, terminales básicos, sistemas de gestión de red, etc.- y por funciones horizontales -fabricación, instalación y comercializaciónagrupadas en divisiones. A la entrada del siglo xxI, una nueva reestructuración vino a satisfacer a una clientela ávida de soluciones integradas eficaces, ágiles y portadoras de valor añadido creciente. Amper adquirió un nuevo perfil como proveedor de soluciones tecnológicas llave en mano (Amper, 2000, p. 1; 2002, p. 5).

${ }^{30}$ Los gastos se destinaron a la I+D, la calidad y seguridad industrial, el fomento de la competitividad y el fomento de la innovación (Intervención General de la Administración del Estado, Congreso de los Diputados, 384, 4-7-2002, pp. 222-225). Alcatel-SESA recibió el 1,36\% de los recursos financieros destinados a la reconversión industrial en España hasta 1987, mayoritariamente en forma de créditos y avales del $\mathrm{BCl}$ (77,6\%), equivalentes al 49,64\% de la construcción naval y el 2,71por ciento de la siderurgia integral (Ministerio de Industria y Energía, 1987, p. 67). Para un solo año -1985- las ayudas por prestación y cotización a la seguridad social recibidas por el Grupo ITT afectaron al 6,15\% del número total de beneficiarios y se cifraron en el 2,94\% de las cantidades totales asignadas (BOE, 27-6-1990, 59, p. 95). Una enumeración crítica de las ayudas a Alcatel incluía ayudas públicas directas -numerosos créditos subvencionados, apoyos en I+D y en formación, así como cuantiosos beneficios fiscales-, colaboración privilegiada de Telefónica, flexibilidad en la aplicación de los planes laborales y muy favorables expedientes de empleo, al abrigo de la reciente reforma laboral, sin olvidar el reiterado montante de 160000 millones de pesetas (DSAM, 219, 3-10-1996, IV Leg, p. 5701; 333, 3-3-1997, p. 8835).

${ }^{31}$ Comparecencia del secretario general de Empleo, Ramón Pimentel (DSCD, 183, 7-4-1997, p. 5061). Entre 1992 y 1996 España concedió a la industria el 3,179\% de la ayuda estatal total de la Europa de los 12. El porcentaje de la ayuda estatal a la industria sobre el valor añadido se cifró en el 1,8\% en 1992-1994 y en el 2,7\% en 1994-1996, niveles por debajo de la Europa de los 12, idéntico perfil a la ratio ECU/persona empleada (1992-1994: 512; 1994-1996: 937) (European Commission, 1998, p. 16).

${ }^{32}$ El PP propugnaba sustituir las políticas activas de fomento industrial a base de programas sectoriales con aportaciones públicas o subvenciones por medidas de estabilidad macroeconómica y flexibilización de la
La reestructuración mundial de la industria de los equipos de telecomunicaciones inaugurada en la década de 1980 había llevado a la recomposición de su estructura oligopólica. Bajo la dirección de una fracción nacional-francesa, en el escenario mundial apareció un nuevo gigante, Alcatel N. V., resultante de la absorción de la rama industrial de IT\&T por la francesa CIT-Alcatel. Este lance alteró el ranking de empresas de equipos de telecomunicaciones -en 1989 Alcatel N. V se aupó a la primera posición por ventas en el ranking europeo-, manteniendo la desintegración industria/servicio. En este proceso, España, cada vez más integrada en la economía mundial, desempeñó un papel importante y distintivo por razones históricas, es decir, por la notable y extensa presencia de la multinacional norteamericana IT\&T en el territorio ${ }^{33}$.

Una vez integrada SESA en Alcatel N. V. como Alcatel-SESA, lanzó un plan quinquenal 1987-1991 sobre la base de expectativas optimistas. Las previsiones de ventas se vieron rebasadas con holgura gracias a la fuerte demanda de Telefónica, que suponía más de las cuatro quintas partes de la facturación total de Alcatel-SESA ${ }^{34}$. Pero la tendencia halagüeña no se mantuvo, sino que se desplomaron las compras de Telefónica y de los restantes clientes del mercado interior. Al finalizar el plan quinquenal, la demanda de equipos procedente de Telefónica había caído veinte puntos porcentuales respecto al nivel más alto alcanzado al final de la década de 1980.

Por si fuera poco, la competencia se acentuó. Por esos años, Alcatel-SESA acaparaba el suministro de software y repuesto para conservación de centrales PC-2000, así como para el acceso al sistema de telefonía móvil celular TMA 900-A. Sin embargo, debía compartir el suministro de equipo de transmisión y radio con tres multinacionales (Telettra España, Ericsson y AT\&T Network Systems -AT\&T-NS-, cabeza de puente de la multinacional norteamericana en Europa) y el equipo de conmutación con otros dos proveedores predominantes -Intelsa (43,25 \%) y AT\&T-NS España (15,22 \%)-. El buen comportamiento de las exportaciones no compensaba plenamente la caída de la demanda señalada. Alcatel-SESA procuró limitar los daños de una demanda incierta diversificando su clientela tradicional y reforzando el papel de algunas secciones o grupos

economía. Esta orientación toleraba medidas de apoyo temporal a ciertos sectores con aportaciones de la UE y con programas horizontales para la adaptación competitiva de las empresas, basados en diferenciación del producto, más allá del precio, entre ellos diseño, calidad, desarrollo tecnológico, marcas e internacionalización: Intervención del ministro de Industria (DSCD, 5-6-1996, pp. 175-176).

33 La intervención en la reconversión de las filiales españolas de IT\&T se remontaba a la decisión de la Comisión Delegada del Gobierno para Asuntos Económicos de julio de 1982 de apoyar dicha reconversión con medidas fiscales y financieras, conjugadas con el esfuerzo de los accionistas y las empresas: Ministerio de Industria y Energía (1983), pp. 214-216. Para mayor desarrollo de los aspectos teóricos, véase Calvo (2017b).

${ }^{34}$ Se preveía un aumento de la demanda de Telefónica, pero menos acusado en 1990 (ElP, 10-5-1989). SESA pensaba remontar en 1993 sus pérdidas del año anterior, en contraste con la situación negativa de sus competidores Ericsson, AT\&T y Amper (Bit, 83, septiembre-octubre de 1993, p. 23). Recuérdese que un primer plan de reconversión multipartito -Gobierno, multinacional IT\&T, CTNE y sindicatos-, cimentado en la ley de 1984 y trabajosamente cerrado en 1986, hubo de ser revisado al tomar el relevo Alcatel N. V. (Libros de Actas del Consejo de Administración de Telefónica, LACA, 19-12-1984, 27-3-1985 y 30-1-1985; Ministerio de Industria y Energía, 1987, pp. 76-77; Ministerio de Industria y Energía, 1984, p. 117. 
operativos, como sucedió con el de redes públicas de conmutación ${ }^{35}$

La política expansiva de Alcatel N. V., plasmada en el fortalecimiento de su sección de transmisión con las adquisiciones de la italiana Telettra, de la alemana AEG KABEL y de la británica también cablera Standard Telephones and Cables (STC), obligó a la casa madre a inyectar de nuevo capital en la filial Alcatel-SESA, que, a su vez, se vería forzada a realizar enormes provisiones de fondos más tarde ${ }^{36}$.

\section{Alcatel-SESA ante los nuevos desafíos a partir de la década de 1990}

A partir de la década de 1990, la industria española fue sometida de forma creciente a lo que se dio en llamar «tensión competitiva", causada por los pilares primordiales de la escena internacional -globalización y cambio tecnológico-37. La evolución, sin embargo, no fue lineal. En su conjunto, la industria española exhibió tasas de crecimiento del empleo negativas en el nefasto trienio 1992-1994 -acordes con la profundidad de la crisis, que desembocó en la desaparición de AHV o de algunos astilleros- y positivas en los años restantes de la década. Por su parte, el grupo de industrias en que estaba incluido el sector de equipos de telecomunicación presentó ligeras discrepancias en materia de empleo: tasas de crecimiento negativas en la primera mitad de la década de 1990, con la excepción de 1995 , y positivas en la segunda mitad, excepto la correspondiente a 1996. El empleo en el sector de tecnología avanzada -material y equipo eléctrico, electrónico y óptico- cayó a menos de la mitad ${ }^{38}$.

Tras arrostrar la incertidumbre del mercado al final de la década de 1980, en la siguiente Alcatel-SESA se vio inmersa en procesos de cambio de diverso tipo, empezando por la estructura de la propiedad. Hacia finales de 1994, la matriz Alcatel $\mathrm{N}$. V. se convirtió en dueña casi absoluta de la filial española al adquirir el 13,24 \% del capital social en poder de Telefónica. Con esta adquisición, una de las facetas de la reestructuración, reforzaba sus posiciones, mientras que en su desinversión Telefónica se atenía a las recomendaciones de la Comisión Europea y persistía en la política de desprenderse de sus par-

\footnotetext{
${ }^{35}$ LACA, 25-5-1992 y 25-7-1992; Alcatel Standard Eléctrica, Memoria(s) Anual(es). La demanda de equipos que Alcatel había recibido de Telefónica para $1992-290000$ líneas telefónicas- no alcanzaba el tercio de su capacidad de producción (Les Échos, 24-12-1991).

${ }^{36}$ European Commission, Case No IV-M.165, Alcatel-AEG KABEL, Document 391M0165, 18-12-1991. Las plantas de cables de Alcatel se localizaban primordialmente en Francia y en Australia; STC estaba implantada en el Reino Unido, en EE. UU. y en Australia (Monopolies and Mergers Commission, 1994, pp. 20-21). Standard Telephones and Cables, fabricante de equipos de telecomunicación, fue una de las empresas europeas absorbidas por IT\&T al adquirir los activos de Western Electric fuera de los Estados Unidos. Protagonizó la transición de las centrales telefónicas automáticas a las electrónicas.

${ }^{37}$ Ministerio de Industria y Energía (1996-1997, p. 333).

${ }^{38}$ Banco de España (2000, p. 110). Esta imagen contrasta vivamente con el aumento generalizado de la producción, importaciones y exportaciones de equipos de telecomunicaciones en España entre 1992-1996 defendido por el Cluster Competitividad (1998, p. 27). Hacia finales de la década de 1990, la producción de equipos de telecomunicación en España se cifraba en 381469 millones de pesetas, que representaban el 10,91\% del sector TIC del país en 1997 (EOI, 1999, p. 274).
}

ticipaciones en empresas industriales proveedoras ${ }^{39}$. Los segundos cambios procedían de la inserción en la matriz Alcatel N. V., ejemplo de los cuales fue el giro impuesto desde la cúpula de la multinacional con la entrada del politécnico Serge Tchuruk, curtido en el sector energético, en sustitución del enarca (École Nationale de l'Administration) P. Suard, ambos, por tanto, genuinos representantes de los cuadros formados en las escuelas francesas de élite. Unos terceros emanaban de novedades organizativas dentro de la filial, léase la conversión de Alcatel-SESA en el holding Alcatel España, amalgama de las filiales (Alcatel CITESA, Alcatel Espacio, Alcatel Sistemas de Información, Alcanet International España y Formación y Consultoría, SA-FYCSA), junto a otras empresas presentes en Espa$\tilde{n} a^{40}$. Desde el punto de vista estratégico, pese a las imposiciones, Alcatel España abogó por una autonomía efectiva dentro de su grupo multinacional como vía para competir por el desarrollo en exclusiva de sus propios productos ${ }^{41}$. Dentro de estos planteamientos, la «internacionalidad» era una de las estrategias preferentes, expresada en uno de sus aspectos más habituales por la exportación.

Sintetizando, en la filial española sucesivamente de IT\&T y de Alcatel, entre 1984 y 1996 se sucedieron reajustes de empleo, concertados de forma tripartita -empresa, sindicatos y Gobierno-, que requirieron un enorme esfuerzo económico y social en créditos subvencionados, prestaciones por desempleo o jubilaciones anticipadas e inversiones para I+D. En tres ajustes sucesivos, SESA perdió un porcentaje elevado de su volumen. La figura 1 da fe del drástico proceso de adelgazamiento de la fuerza laboral y de la especial crudeza que tuvo en la segunda mitad de la década de 1980. La plantilla total de Alcatel España volvió a menguar hasta verse reducida a 4022 en el año 2000 y a 881 seis años más tarde ${ }^{42}$.

39 Tan solo un $0,38 \%$ permaneció en manos de varios accionistas españoles; el precio pagado fue de 22235 millones de pesetas (Libros de Actas del Consejo de Administración de Telefónica, 26-10-1994; Alcatel Standard Eléctrica, 1987, p. 6; CNMV, Hecho relevante, 4164, 19-10-1994; $A B C, 11-1-1997)$. Sin duda por error, Telefónica recoge la venta a Alcatel N. V. del 3,24\% del capital social en SESA (Telefónica, Memoria anual 1995, p. 133).

${ }^{40}$ Las otras empresas presentes en España eran: Cegelec Ibérica, Saft-Nife Ibérica, Alcatel SEL Señalización, Alcatel Cable Ibérica y Alcatel Contracting. Saft Nife Ibérica, filial de la multinacional francesa Saft, se constituyó en el año 1996 por fusión de Nife (1929) y Saft Ibérica (1972) y se convirtió en líder ibérico en sistemas de alimentación eléctrica y baterías. La empresa tenía una única planta en Vitoria y una red de delegaciones en toda la Península; sus fabricados integraban productos Saft procedentes de Francia, Alemania, Inglaterra y Suecia (ElP, 21-2-2000).

${ }^{41}$ PCWorld, 1-2-1997; Espina (1995, p. 73). Alcatel España absorbió a Alcanet International España en 2002 sin ampliación de capital de la sociedad absorbente (BORME, 124, 3-7-2002, p. 17658).

${ }^{42}$ El coste estimado de la reestructuración de actividades, fábricas y plantillas de la citada empresa se cifró en unos 160000 millones de pesetas. Según una cifra no contrastada, en la última reconversión cada puesto de trabajo suprimido supuso una indemnización media de 18 millones de pesetas (DSAM, 219, 3-10-1996, IV Leg, p. 5701; ElP, 4-7-1996); pequeños matices en las cifras: unos 10000 puestos de trabajo perdidos y 150000 millones de pesetas para financiar las reconversiones (La Tribune, 26-9-2008). Sorprende que algunos documentos oficiales dieran un tratamiento informativo menor a la reducción de plantillas en la industria aquí estudiada (Aprobación por los Plenos del Senado y del Congreso del Dictamen de la Comisión Mixta para las Relaciones con el Tribunal de Cuentas correspondiente a la Cuenta General del Estado de 1985, BOE, 27-6-1990, Serie E, núm. 59). 


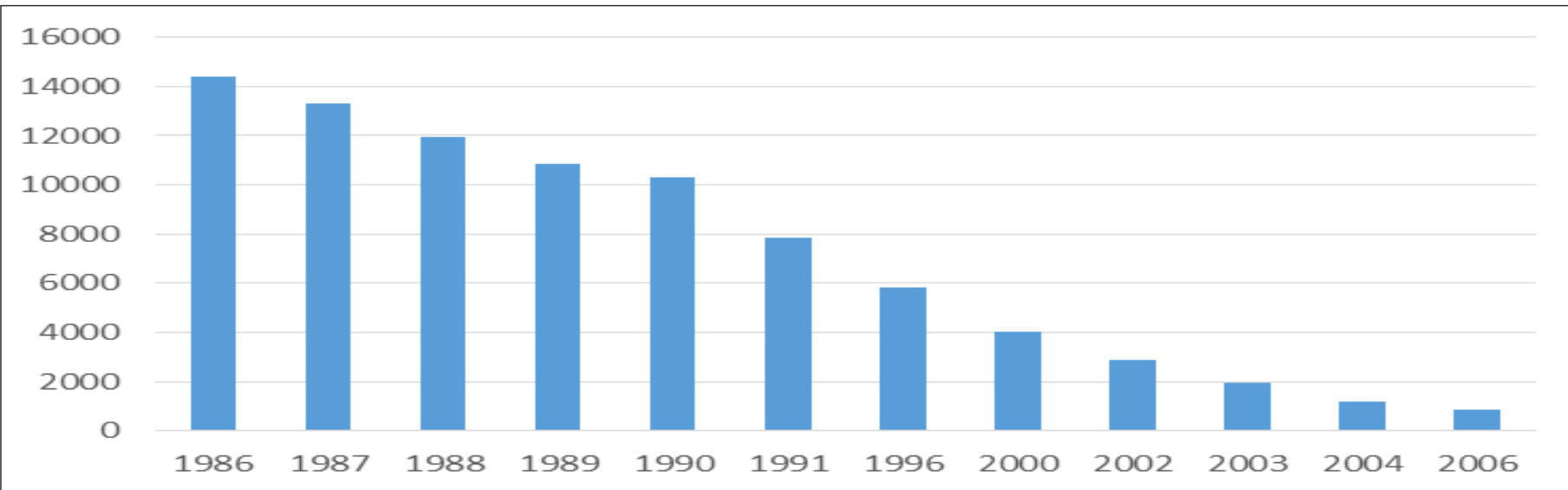

Figura 1. Evolución de la plantilla de Alcatel en España, 1986-2006

Fuente: elaboración a partir de Alcatel, Memoria(s) anual(es).

El autocalificado "gran impulso de reestructuración» de la multinacional Alcatel N. V. durante la era Tchuruk, iniciada en 1995 y coincidente con el final de la era socialdemocracia y la llegada a la presidencia del neoliberal Jacques Chirac, repercutió de manera desigual en las plantas europeas. En España, la nueva cultura de empresa impuesta por la matriz llevó a profundizar el proceso de reconversión iniciado al comienzo de la década anterior ${ }^{43}$. Si bien es cierto que la destrucción de puestos de trabajo afectó a la generalidad de los países en que Alcatel mantenía una presencia, por cierto muy dispar, en España cobró una intensidad mayor. Alcatel redujo la plantilla total en casi un $80 \%$, es decir, en un -15,3\% de variación anual acumulada. En pleno azote de la reestructuración, entre 2000 y 2002, el porcentaje de la mano de obra empleada por Alcatel España pasó del 5,98\% al 4,62 \% del conjunto del grupo ${ }^{44}$.

Solapándose en años seleccionados para establecer la situación de la empresa y enmarcado en la transformación de la matriz Alcatel N. V., el Plan Estratégico de 1994-1998 promovido por Alcatel-SESA contemplaba cierres, integración de actividades e inversión con el objetivo de lograr beneficios de explotación. Tales propósitos se presentaban bajo el ropaje de innovaciones organizativas dentro de un cambio cultural de gran calado, poniendo el trabajo en equipo como instrumento y la mejora permanente como norte ${ }^{45}$.

Durante el despliegue del mencionado plan, justamente en 1995, Alcatel-SESA arrostró pérdidas por unos 30000 millones de pesetas, cifra que las previsiones para el año siguiente vaticinaban igualar. Esas pérdidas, sumadas a los excedentes de

${ }^{43}$ Canalejo (1995); Canalejo (2005, pp. 51-60); Chakravarthy (1996, p. 532).

${ }^{44}$ Observatorio Industrial de Electrónica, Tecnologías de la Información y Telecomunicaciones (2008, p. 25). En Italia, se llegó a un acuerdo tripartito Gobierno-empresa-sindicatos; en Francia y en Alemania se abrió un proceso de negociación (Dolores García-Hierro Caraballo, DSCD, Comisiones, núm. 183, 7-4-1997, p. 5062). Europa tenía una tasa de sindicalización relativamente baja en el sector de las TIC (EurWORK, 2002).

45 Alcatel se comprometía a inyectar en su filial española 52000 millones de pesetas en una ampliación de capital, como así llevó a cabo el año anterior a la finalización del plan (ElP, 15-8-1996; Computer Business Review, 9-7-1996); las centrales sindicales opusieron resistencia y convocaron una huelga (Libération, 16-8-1996). plantilla, el efecto del cambio tecnológico acelerado y la globalización de la economía llevaron a la filial española a plantear una serie de medidas de reajuste de plantillas y en los centros de producción. En primer lugar, comprendían un expediente de regulación de empleo (ERE) que afectaba a algo más de novecientos trabajadores, la mayoría en forma de jubilaciones anticipadas (450), pero también con regulaciones temporales (290) y rescisiones de contratos (188), estas últimas sustituidas finalmente por la primera modalidad tras el acuerdo entre la empresa y los trabajadores. Incluían además el cierre de las plantas de Arteixo (La Coruña) y Torrejón (Madrid), para concentrarse en la producción de equipos de conmutación (centrales telefónicas) y acceso (enlace entre las centralitas y el abonado) en sus fábricas de Villaverde, en la zona sur de Madrid, y de Toledo.

Debido a idéntica situación de pérdidas cuantiosas, se sucedieron bajas voluntarias en Alcatel España. Alcatel reformuló el plan existente con un nuevo plan trianual con plazo final en 1998 de contenido laboral -rescisión de 1338 contratos y congelación salarial-, y de reestructuración de activos -reconversión, enajenación de bienes y algunas operaciones urbanísticas-.

Las autonomías en las que Alcatel estaba implantada no fraguaron un frente común anticrisis. Galicia, Andalucía y Castilla La Mancha se opusieron a la rescisión de contratos presentada por la empresa, e, incluso, ofrecieron alternativas positivas al cierre. En el debate de las Cortes de Castilla La Mancha, que acusaba el cambio de ciclo político con la llegada del PP al Gobierno central, se resaltó el carácter no pactado de los despidos, algo inédito hasta el momento ${ }^{46}$. La primera fue, sin duda, la más audaz. En 1995, el Parlamento de Galicia declaró la unidad productiva de Alcatel-SESA, entonces ubicada en el polígono industrial coruñés de Sabón-Arteixo, como una «necesidad estratégica» en una resolución que instaba a la Xunta

\footnotetext{
${ }^{46}$ Se subrayaba que «la reconversión siempre ha sido acordada, ha sido pactada con los representantes de los trabajadores mediante sistemas de prejubilaciones, bajas incentivadas, planes de renta, ayudas de la propia Administración, con una serie de subvenciones a fondo perdido, expedientes de regulación temporal de empleo, etc., participación de Telefónica en los acuerdos, con volúmenes de pedidos» (Intervención del portavoz de Izquierda Unida, Diario de Sesiones de las Cortes de Castilla la Mancha, DSCCLM, 17-10-1996).
} 
de Galicia la ejecución de las acciones adecuadas para garantizar el mantenimiento del centro y consolidar su futuro en la comunidad autónoma ${ }^{47}$. Más aún, directamente en el salvamento de la planta al decidir una inversión minoritaria en una empresa de capital mixto -Arteixo Telecom (ArTel)-, creada en 1996 por fusión de dos proyectos empresariales. Dicha inversión perseguía un plan industrial sólido con la participación accionarial de control de la madrileña Gesprotel (ejecutivos de Alcatel, $51 \%$ ) junto a las minoritarias de Sodiga (Xunta de Galicia, $20 \%$ ) y de un socio industrial y tecnológico (Intelega, $29 \%$ ). El drenaje de recursos para mantener las instalaciones y la continuidad de Arteixo Telecom alcanzó a los propios trabajadores, que en 1996 aportaron soporte financiero. Al cabo de tres años, ArTel emprendió una reestructuración que se saldó con la segregación de la empresa y la creación de un nuevo grupo empresarial, Global Diez. Así, ArTel pechó con el desvío de la carga de trabajo principal al nuevo grupo empresarial y con una descapitalización al tener que soportar un crédito de cerca de 3 millones de euros, reduciendo la participación de Gesprotel en un 31\%. En 2005, ArTel, aduciendo dificultades financieras y la necesidad de capitalización, decidió vender el suelo de este centro de trabajo y transferir todo el personal a otra localidad gallega, hecho que supuso el cierre del centro de Arteixo ${ }^{48}$

Las autoridades regionales, tibias en la defensa del empleo, hubieron de afrontar críticas aceradas procedentes de la oposición. En la Asamblea de Madrid esta denunció el rechazo del Gobierno autonómico del PP a una declaración institucional de apoyo al proceso negociador en que estaban inmersos los trabajadores de Alcatel, postura que despejaba el «camino de la imposición traumática» y unilateral elegido por la empresa. La oposición achacaba asimismo a la alta dirección internacional de Alcatel, que, con la pasividad del Gobierno regional, diese a España el trato de país periférico y concentrase en la Comunidad Autónoma de Madrid la producción de los obsoletos sistemas de conmutación, a la par que la excluía de la fabricación de productos estrella, tecnológicamente punteros, reservados a otros países (Alemania, Italia y, especialmente, Francia). Al mismo tiempo, la estrategia del empleo de la multinacional era notablemente discriminatoria para España en cuanto al número de excedentes de plantillas planteados por la empre$\mathrm{sa}^{49}$. La oposición echaba en cara al Gobierno autonómico que refrendase la política de la empresa aun a sabiendas de la alta concentración de despidos en Madrid -aproximadamente dos tercios del total de los previstos en el país-, del plan de cierre total de la factoría de Torrejón de Ardoz, en pleno Corredor del

\footnotetext{
47 Diario de Sesións do Parlamento de Galicia, 54, IV lexislatura, Serie Pleno, 22-3-1995, p. 3800.

48 Boletín Oficial do Parlamento de Galicia, 765, 13-4-2005, p. 50196. La iniciativa permitió a la Xunta rechazar la ausencia de defensa del tejido industrial gallego (DSPG, 71, 14-9-1999, p. 5382). Aportaciones de los trabajadores: unos 600 millones de ptas. de sus indemnizaciones, un promedio de un año de desempleo y una disminución del $20 \%$ en sus salarios a través del plan de apoyo social (Boletín Oficial do Parlamento de Galicia, 743, 11-3-2005; 765, 13-4-2005, pp. 50194-50196). Rafael Valcarce, presidente de ArTelecom hasta la entrada de Global Diez, amplía la nómina de salvadores de la fábrica a los alcaldes gallegos. El nuevo centro de producción de ArTelecom se instalado en el municipio de Las Pontes.

${ }^{49}$ Cuando Alcatel N. V. anunció su reestructuración, de los 20000 puestos de trabajo para suprimir en todo el mundo, el 6,5\% correspondían a España, entre ellos unos 800 en Villaverde (El País, 25-10-2001).
}

Henares, considerado de interés preferente, de la ausencia de compromiso de fomentar la producción en Madrid y de la falta de un plan industrial capaz de despejar incertidumbres del futuro, a corto y medio plazo ${ }^{50}$.

La planta de Toledo fue sometida en 1997 a un proceso de reconversión y a un plan estratégico para dar un mayor impulso a la producción e incrementar la productividad y calidad. Una vez más, la petición de rescisión de contratos se fundamentaba básicamente en razones técnicas, organizativas y, sobre todo, en los costes de personal y exceso de plantilla ${ }^{51}$.

La posición de los trabajadores con el despido forzoso de medio centenar de los más de 500 previstos provocó sucesivamente un clima de enrarecimiento y de conflictividad laboral a finales de 1996, seguido de una espiral huelguística de organización sofisticada - por centros y por días- y comportamientos duros, de sanciones a los implicados en incidentes y un encono de la conflictividad. Nuevas negociaciones despejaron el camino a un acuerdo sobre la necesidad de seguir negociando y sobre las fórmulas de arbitrar y dirigir esta negociación ${ }^{52}$.

Los problemas de fondo persistieron. En una nueva cuenta del largo rosario, Alcatel España acometió en 2003 un ERE que afectó a 395 trabajadores y se amplió al año siguiente, con la supresión del 6,3\% de una plantilla ya fuertemente disminuida (figura 1). En esta ocasión, el ERE contemplaba un plan de outplacement, que incluía servicios de reciclaje y recolocación para reconducir las carreras profesionales. A estos dos ERE de 2003-2004 les siguieron expedientes anuales sucesivos. Se había dado un nuevo paso hacia estrategias acordes con la globalización ${ }^{53}$.

\section{La globalización y la estrategia fab-less de Alcatel N. V. en España}

A juicio de uno de los especialistas más reconocidos, la globalización de la economía generó situaciones diversificadas según la forma en que los países se insertaban en ella. Las

\footnotetext{
${ }^{50}$ Resultaba revelador que la planta de Villaverde se dedicara a un producto amenazado de pronta obsolescencia (Diario de Sesiones de la Asamblea de Madrid, DSAM, 219, 3-10-1996, IV Leg, pp. 5699, 5671 y 5702). Según los defensores del efecto frontera, el traslado de Alcatel de Torrejón de Ardoz a Toledo obedecía a una mayor disponibilidad y baratura de suelo industrial -la mitad que en Madrid- en los polígonos industriales de Toledo (Lissavetzky Díez, DSAM, 672, 29-30-9-1998, pp. 18307 y 18310). En la III Legislatura, Izquierda Unida (IU) y el PSOE gobernaron en coalición la Comunidad Madrid, que pasó a manos del PP tras las elecciones autonómicas de mayo de 1995.

${ }^{51}$ El presidente de Alcatel en España achacaba la mala situación al exceso de fábricas. De las seis existentes -la histórica de Madrid, sede de la empresa, había sido destinado a oficinas- dos funcionaban a plena satisfacción -Málaga y Villaverde I- y otras cuatro -Toledo, Arteixo, Torrejón y Villaverde II- trabajaban por debajo de su capacidad y con sobrecostes (Computerworld, 3-3-1995). En la configuración de comportamiento de Alcatel-SESA empezó a asomar el fantasma de operaciones urbanísticas en Torrejón y Madrid, tildadas por algunos de especulativas (DSCD, Comisiones, 183, 7-4-1997, p. 5062; DSAM, 219, 3-101996, IV Leg, p. 5699). En 1995, varios miles de trabajadores de la empresa iniciaron movimientos de protesta (ABC, 7-4-1995; El País, 7-4-1995).

${ }^{52}$ Entre otras, la incorporación de algún experto ( $D S C D$, Comisiones, 183, 7-4-1997, p. 5061).

53 Computing, 23-2-2004; Cinco Días, 20-2-2004 y 6-7-2001; Observatorio Industrial deElectrónica, Tecnologías dela Informacióny Telecomunicaciones (2008, p. 25.) El ERE de 2004 iba dirigido selectivamente a ingenieros de 35
} a 45 años, con indemnizaciones. 
naciones tecnológicamente avanzadas y competitivas - EE. UU., Escandinavia y Francia, entre otras- tenían todas las bazas para llevarse la parte del león de los empleos de alta cualificación en perjuicio de los países de nueva industrialización -Singapur, Taiwan, China, etc.-. Por su parte, los países sin la capacidad tecnológica o profesional de hacer innovación y diseño a nivel de punta presentaban una mayor exposición a impactos drásticos de la nueva reorganización productiva. En medio quedaban los países, entre ellos España, con capacidades de fabricación tradicional y de buena calidad, pero cara debido a costes sociales comparativamente más altos que en el segundo grupo de países ${ }^{54}$. Ya hemos visto, con todo, que la línea de demarcación podía verse difuminada hasta el punto de tratar a un país como España como de nueva industrialización. Expresión de la globalización fue la estrategia fab-less, léase el trasvase de la producción a empresas más eficientes en la fabricación final de ciertos productos y el abandono del suministro e instalación por la provisión de soluciones integrales a la clientela.

En España, la estrategia fab-less, impuesta por la casa madre Alcatel N. V. contra la pretendida autonomía de las filiales nacionales, se plasmó en la venta o segregación de diversas fábricas. Así, fueron vendidas las plantas de Maliaño (Cantabria) y la malagueña de CITESA -2000 trabajadores-, segregada de Alcatel con el nombre de A-Novo. En octubre de 2001, ante la baja utilización de las capacidades de producción y su evolución previsible, Alcatel decidió desinvertir en las fábricas de Villaverde y Toledo. El mecanismo utilizado en la planta de esta segunda consistió en concentrar en ella la actividad industrial y venderla a continuación a la multinacional californiana Sammina-SCI Corporation, un proveedor líder de soluciones de fabricación integradas, con el compromiso de que Alcatel la mantendría durante cuatro años como proveedor exclusivo de cable y fibra óptica. Fue un episodio efímero: la planta toledana, calificada de estratégica en Europa al principio, vio menguar su plantilla a menos de la mitad y, acabado el plazo acordado, echó el cerrojo ${ }^{55}$. De escasa utilidad resultaron las diversas iniciativas parlamentarias y los pronunciamientos a favor del mantenimiento del empleo en las Cortes de Castilla la Mancha y otros organismos como el Ayuntamiento de Tole$\mathrm{do}^{56}$. A finales de 2001, el centro puntero en tecnología telefó-

\footnotetext{
${ }^{54}$ Castells (2002 pp. 31-32). Se ha escogido expresamente una contribución en un órgano de difusión sindical.

55 New York Times, 25-1-2002. En 2004, Sanmina trasladó a Toledo parte de la producción de su planta de Suecia (Cinco Días, 24-4-2004). Cuando terminó el contrato con Alcatel, Sanmina deslocalizó la producción a Hungría y China. La segunda fue la fábrica de Arteixo, en la Coruña, a la que se añadió la pequeña planta de baterías de Vitoria (Saft). Alcatel puso en venta un área de la fábrica de Villaverde dedicada a la fabricación de convertidores. En estas dos unidades trabajaban un centenar de personas. Los 1300 despidos con que las ventas se saldaron fueron de carácter voluntario para trabajadores mayores de 50 años, con 45 días por año trabajado; para el resto de la plantilla la empresa estableció subidas salariales vinculadas a objetivos. La Comisión Europea determinó no oponerse a la concentración por adquisición de plantas (European Commission, Case No COMP-M.2734-SANMINA-SCI-Alcatel REGULATION EEC, 4064-89, 21-3-2002).

${ }^{56}$ El Gobierno autonómico reconoció contactos con Sanmina, con los representantes legales de la empresa -despacho Cuatrecasas-, con el delegado de Trabajo y Empleo de Toledo y con los agentes sociales -UGT, CC. OO. y comité de empresa (consejera de Trabajo y Empleo, Magdalena Valerio Cordero, DSCCLM, 24-10-2005, p. 22). En una moción conjunta, tres grupos (PP-PSOE-IU) del Ayuntamiento de Toledo expresaban su
}

nica de Villaverde se desmanteló y trasladó parcialmente la producción y algunos efectivos a Toledo, previamente planta de acogida de trabajadores desplazados por cierres de otras ${ }^{57}$.

Alcatel tenía el propósito de concentrar su actividad de I+D en España, de reducir paulatinamente la ingeniería de sistemas de conmutación tradicionales y, contrariamente a los planes anteriores, de cesar por completo sus actividades de ingeniería de acceso radio, con un recorte añadido de empleos ${ }^{58}$.

Con diferencias destacables respecto a lo que sucedía en otros países en que Alcatel N. V. estaba implantada, en España Alcatel sufrió un intenso proceso de disminución de activos y descapitalización. Lo atestigua el descenso del inmovilizado material -edificios y terrenos, incluida la sede central en Madrid, así como de instalaciones técnicas y maquinaria-. Paradójicamente, la rentabilidad de la empresa en España superaba con creces la del grupo a nivel internacional. La subcontratación aumentó notablemente entre 2000-2006, de forma que la ratio de los otros gastos externos sobre la facturación se sextuplicó ${ }^{59}$. Finalmente, con la externalización la empresa dejó de ser industrial para convertirse básicamente en comercial. Ello trajo consigo un cambio del tipo de puesto de trabajo. Aunque quienes los ocuparon seguían siendo, en su mayor parte, ingenieros y técnicos superiores con experiencia, dejaron de hacer tareas técnicas de investigación y mantenimiento, lo que supuso en sustancia una grave pérdida y desperdicio de capital humano ${ }^{60}$.

Es hora de examinar, brevemente, la etapa inaugurada en 2006 con la creación de Alcatel Lucent por fusión de Alcatel N. $\mathrm{V}$. y la norteamericana Lucent Technologies, que dio origen al líder mundial en el suministro de soluciones de comunicación y reforzó la estructura oligopólica del sector. En la era Tchuruk, Alcatel había adquirido una estructura matricial compleja, asentada en organizaciones geográficas y en segmentos de actividad. Las primeras se dividían en tres áreas -Europa y Sudamérica, EE. UU. y Asia/Pacífico- y, dentro de cada una, el énfasis recaía sobre la parte comercial y la cadena de suministros, es decir, el área de relación con el cliente. Los segmentos de actividad comprendían networking, internet y óptico, empresas y consumo, cables y componentes. A su vez, cada seg-

rechazo al cierre de la factoría de Sanmina y el apoyo a la plantilla en las acciones que realizasen en defensa de los puestos de trabajo. Asimismo, ofrecían la mediación del Ayuntamiento en la búsqueda de una solución al conflicto y decidían adoptar todas las medidas pertinentes para evitar cualquier intención especulativa sobre los terrenos de la factoría (Acta de la sesión ordinaria, Ayuntamiento de Toledo, 20-10-2005).

57 ABC, 6-2-2002

${ }^{58}$ PC World, 18-10-2001; Computerworld, 18-10-2001. Ello implicaba desplazar unos 200 empleos de la fábrica de Villaverde a la de Toledo y unas 300 bajas (mensaje del presidente, 17-10-2001).

59 Observatorio Industrial de Electrónica, Tecnologías de la Información y Telecomunicaciones (2008, p. 23). En el Senado se denunciaba que Alcatel subvencionaba e incentivaba las subcontrataciones y, por tanto, la economía sumergida, refiriéndose en este caso a Alcatel CITESA (Diario de Sesiones del Senado, DSdS, 66, Sesión del Pleno, 7-5-1991, pp. 3605-3606).

${ }^{60}$ Hacia 2008, los gastos de personal únicamente representaban el $15 \%$ de la facturación. Plantilla compuesta predominantemente por personal cualificado (54,6\% de titulados superiores, un 33,3\% de titulados medios, un $6,6 \%$ de técnicos y un $5,5 \%$ de administrativos y subalternos), con una edad media en torno a los 40 años (Observatorio Industrial de Electrónica, Tecnologías de la Información y Telecomunicaciones, 2008, p. 28). Estudios de otros sectores remachan esta idea del empeoramiento de las condiciones de trabajo, unidas a las reducciones de los niveles de empleo (Trappman, 2013, p. 1; Gazier y Brugeman, 2008). 
mento contenía divisiones especializadas en los productos correspondientes, con responsabilidad en toda la extensión del producto -gestión e ingeniería de I+D, entre otras-. Con los cambios acaecidos, el peso de la potestad que emanaba de las divisiones de producto, por un lado, y de las áreas geográficas, por otro, se había equilibrado en parte ${ }^{61}$.

Alcatel España, ahora bajo el nombre de Alcatel-Lucent España, echó a andar en diciembre de 2006 con 881 trabajadores (figura 1) ${ }^{62}$. Alfredo Redondo, su máximo responsable, insistía en situarla en el marco de un cambio sustancial en la cadena de valor y de la sociedad de la información. En resumidas cuentas, venía a aceptar la ya descrita estrategia fab-less para lograr mantener su protagonismo en el sector, al nivel de los 770 millones de facturación de 2002. Desde el punto de vista de los recursos humanos, asignaba cometidos específicos a los cuatro grandes colectivos integrantes. Al comercial le atañía comprender las necesidades de los clientes y al de los ejecutores satisfacerlas con eficacia. A los administradores les tocaba hacer funcionar una empresa adelgazada en su plantilla y redefinir radicalmente los procesos de trabajo. Un papel decisivo le correspondía al último colectivo, el del personal de I+D, responsable de los desarrollos para toda la multinacional en unidades desparramadas por distintos países. Alcatel-Lucent España destacaba por su liderazgo en sistemas de acceso y en señalización ferroviaria, al tiempo que por su notable papel en la industria espacial, en el desarrollo de aplicaciones de telefonía móvil (Barcelona) y en convertidores de potencia. A esta mano de obra, calificada de "industrial», se le encomendaba una misión crucial para el futuro en un país como España y en una etapa de características netamente distintas a las de la precedente. Las escasas expectativas de crecimiento indefinido abocaban a los fabricantes de equipos de telecomunicación a abandonar el "peligroso estado de nostalgia» y a fomentar una estructura empresarial ágil y flexible, capaz de adaptarse en tiempo real a la nueva sociedad de la información ${ }^{63}$.

Lo cierto es que de ese diagnóstico no acababan de emanar directrices claras; las consecuencias, por el contrario, sí lo fueron. Más arriba hemos señalado que, dentro de la incidencia variable de la reestructuración de plantillas en varios países europeos, España había salido castigada en términos relativos $^{64}$. Alcatel-Lucent España se estrenó con una reestructuración organizativa y del personal en diversos niveles. Para empezar, procedió al nombramiento de los principales directivos, al que siguió el nivel de mandos intermedios. Desde el princi-

\footnotetext{
${ }^{61}$ Esa misma organización se reproducía en Alcatel España: Miguel Canalejo era su presidente y, al mismo tiempo, el del área geográfica que comprendía España, Portugal, Brasil y resto de Sudamérica; había cuatro responsables de cada zona (Bit, 121, mayo-junio de 2000). La Comisión Europea dio vía libre a la fusión de Alcatel y de Lucent Technologies (European Commission, Case No COMP-M.4214-ALCATEL-LUCENT TECHNOLOGIES, Regulation (EC) No 139-2004 Merger Procedure). La empresa reafirmaba el carácter estratégico de la fusión (Alcatel-Lucent, 2006, p. 8).

${ }^{62}$ El Economista, 12-12-2006. La fusión añadió nuevas plantas (Alcobendas, de Lucent Technologies).

63 Cinco Días, 3-6-2003. Alfredo Redondo, ingeniero de telecomunicación por la Universidad Politécnica de Madrid y con formación perfeccionada en el IESE y en una de las localidades con presencia de Alcatel en Francia, era responsable de Alcatel España y exhibía fuertes credenciales en el sector de las telecomunicaciones en Latinoamérica (El Economista, 1-122006; 12-12-2006).

${ }^{64}$ European Restructuring Monitor Quarterly, 1, spring 2007, pp. 12-13.
}

pio llevó a cabo un ajuste continuo de la plantilla a las necesidades del mercado, que incluía la absorción del personal de empresas adquiridas -Nortel-, la contratación de trabajadores en nuevas áreas y el trasvase a otras empresas -Thales-. Antes de cuantificar las bajas, Alcatel-Lucent España se propuso fijar las plantas que subsistirían -Alcobendas (Lucent Technologies) y Madrid (Alcatel)- y los criterios de ese mantenimiento -integración de las tareas similares de las dos empresas para evitar repeticiones-. En la sección de I+D, la empresa mantenía los centros de innovación dispersos en el país por cuyo liderazgo en la tecnología de televisión por Internet (Internet Protocol Television: IPTV) apostaba ${ }^{65}$.

La respuesta obrera no se hizo esperar. Una de las dos centrales sindicales mayoritarias -CC. OO.- rechazó por incoherentes los argumentos esgrimidos por la dirección (necesidad de impulsar las sinergias, ahorros y malos resultados económicos) para justificar la medida. Los sindicatos reclamaban el mantenimiento de los proyectos industriales, del empleo y de las inversiones en I+D en las dos plantas de Madrid y Alcobendas. En su razonamiento, la búsqueda de viabilidad pasaba por un proyecto industrial que aprovechase el potencial humano y no por la destrucción gradual de empleo ${ }^{66}$. En definitiva, la empresa imponía las grandes estrategias que los demás agentes apenas si lograban modificar. El ciclo abierto a inicios de la década de 1980 se ampliaba con un nuevo episodio, si bien lejos todavía de sucesos traumáticos venideros como la adquisición de Alcatel Lucent por Nokia, por limitarnos a uno solo.

\section{Conclusiones}

El cambio tecnológico y la liberalización de las telecomunicaciones en todo el mundo provocaron el desmembramiento de los monopolios estatales del servicio telefónico, imperantes en muchos países durante décadas, a la vez que desafiaron el equilibrio existente en los mercados de equipos de telecomunicación. Europa desempeñó un papel importante en la recomposición del oligopolio mundial de la industria de equipos de telecomunicaciones en la nueva etapa. La creciente globalización empujó a una transición de los mercados nacionales protegidos por barreras de entrada a un mercado único europeo en el que los Estados nacionales seguían contando de forma clara.

Este trabajo pretende enriquecer el conocimiento de los procesos de reestructuración a nivel de Estado nación desde la perspectiva de un país no central, con una liberalización tardía y una historia casi inédita. Vista desde España, la reconversión de la industria de equipos de telecomunicaciones fue el resultado de la compleja interacción de múltiples actores, que ejercieron un peso desigual.

A nivel de empresa, se encontraba la multinacional Alcatel N. V., con una estrategia para reconstruir la estructura oligo-

\footnotetext{
${ }^{65}$ España generaba facturación por tres vías: ventas directas en el país, ventas en el exterior de los productos resultantes de la I+D y resultados de las ventas a Telefónica fuera de España. El 90\% de la tecnología ADSL instalada en España era de Alcatel-Lucent, así como el 30\% del tráfico de voz sobre IP; el $80 \%$ de los cables submarinos; el $50 \%$ de la fibra óptica y la tecnología IPTV usada por tres operadoras (Telefónica, ONO y Ya.com). La media de edad de la plantilla de Alcatel-Lucent España no llegaba a 40 años y un tercio de los trabajadores se dedicaban a innovación en los centros propios en España (El Economista, 12-12-2006).

${ }^{66}$ El Economista, 15-2-2007.
} 
pólica del sector; su filial SESA, con presupuesto autónomo, y la operadora Telefónica, que durante un tiempo mantuvo su condición de monopolio semipúblico antes de la privatización y la liberalización del mercado. En la esfera político-administrativa, los Gobiernos de la UE, españoles y franceses -el primero en medio de una reciente integración económica en Europa - y, a su debido tiempo, debido al cambio en el modelo territorial, las Administraciones regionales. Por último, dos sindicatos con cierta influencia, pero con objetivos no siempre compartidos. De modo que la apelación de un estudio de caso en profundidad se encuentra aquí en esta diversa actuación conjunta de múltiples protagonistas con peso e influencia dispares y en la complejidad de las relaciones involucradas, elementos compartidos con especialistas de otros sectores ${ }^{67}$.

¿Qué aporta el caso de un país no central como España al análisis de la reconversión de la industria de equipos de telecomunicaciones? Para empezar, añade una mayor complejidad y elementos distintivos. El desarrollo de su política industrial según el llamado modelo latino, ya fuertemente erosionado, y en un proceso de integración tardía a la UE, otorgó una mayor autonomía al Estado, matizada en cierta medida por la transferencia de poderes del Gobierno central a los organismos regionales o comunidades autónomas. El caso español muestra la motivación en torno a las respuestas de reestructuración a la integración y liberalización europeas, así como una pauta concreta de reconversión.

Vale la pena insistir en las coincidencias y discrepancias entre los actores. Las empresas insistían en la reducción de costes, mientras que los sindicatos propugnaban planes sociales favorables. Gobiernos y empresas coincidían en el aumento de la competitividad, de la misma manera que sindicatos y Gobiernos lo hacían en el mantenimiento de empleo. Precisamente en esa política de mantenimiento de empleo residen las razones de la continuidad de las ayudas públicas.

Dada la importancia de la filial de Alcatel en España, su claro predominio como proveedor de Telefónica y su proyección hacia el mercado latinoamericano, en este país se jugaron en gran medida las cartas del futuro del sector en el mercado mundial fuertemente competitivo. En España se libraron episodios importantes de la batalla de la reestructuración de la industria de equipos. SESA fue una pieza destacada en la configuración de Alcatel N. V. y en la alteración del sector de apoyo al carácter oligopólico. En definitiva, el análisis de la filial de Alcatel N. V. en España se revela como un laboratorio privilegiado para observar cambios sustanciales en el conjunto europeo y mundial.

\section{Agradecimientos}

Este artículo sigue la metodología y planteamientos de Calvo (2017b), comunicación presentada en el seminario organizado por José L. García Ruiz y Jesús M. ․ Valdaliso en la UCM. Agradezco a los organizadores su acogida y a los asistentes sus esclarecedores comentarios. Fue asimismo incluida en la sesión del XII Congreso de la AEHE, Salamanca, en 2017. La versión final corresponde al proyecto HAR2015-64769-P y se adscribe al Centre d'Estudis Antoni de Capmany (UB).

\footnotetext{
${ }^{67}$ Díaz Morlán et al. (2008, p. 184); Viaña (1991). Un marco teórico de la complejidad de las negociaciones internacionales en Weiss (1993, pp. 269-300).
}

\section{Procedencia de la documentación principal citada}

Asamblea de Madrid

Congreso de los Diputados

Comisión de las Comunidades Europeas

Comisión Nacional del Mercado de Valores (CNMV), Madrid

Cortes de Castilla la Mancha

Parlamento de Galicia

Sénat de la France

Telefónica, sede de Telefónica, Madrid

\section{Fuente oral}

Luis Solana Madariaga, conversación con el autor, Madrid, 8-3-2016.

\section{Hemeroteca}

\author{
$A B C$, España \\ AHCIET, Revista de Telecomunicaciones \\ Bit, España. \\ BORME, España \\ Cinco Días, España \\ Computer Business Review \\ Computerworld \\ Computing \\ El Economista, España \\ El País, España \\ El Tiempo \\ European Restructuring Monitor Quarterly \\ Fiber Optics Weekly Update \\ Gazeta Mercantil \\ La Nación, Argentina \\ La Repubblica, Italia \\ La Tribune \\ Le Monde, Francia \\ Les Échos, Francia. \\ Libération, Francia \\ New York Times, USA \\ PCWorld
}

\section{Bibliografía}

Alcatel-Lucent, 2009. Submission to Commerce Commission Discussion Paper on Next Generation Networks, February 2009. Alcatel-Lucent.

Alcatel-SESA, 1991. Memoria Anual 1991. Alcatel-SESA, Madrid.

Amesse, F., Latour, R., Rebolledo, C. y Séguin-Dulude, L., 2004. The telecommunications equipment industry in the 1990s: From alliances to mergers and acquisitions. Technovation. 24 (11), 885-897.

Amper, 2000. Informe del Consejo de Administración sobre la reestructuración societaria del grupo Amper. 16 de febrero. Amper, Madrid.

Amper. 2000a. Reinventando Amper, presentación I. E. A. F, 10 de marzo. Amper, Madrid.

Amper, 2002. Presentación de los resultados del ejercicio 2001. 22 febrero. Amper, Madrid Arpege Group, 1994. Network Management: Concepts and tools, Chapman and Hall, Londres.

Banco de España, 2000. Resultados anuales de las empresas no financieras 1990 1997. Banco de España, Central de Balances, Madrid.

Bartlett, C. A. y Ghoshal, S. S., 1989. Managing Across Borders: The Transnational Solution. Harvard Business School Press, Cambridge MA

Baskoy, T., 2008. The Political Economy of European Union Competition Policy: A Case Study of the Telecommunications Industry. Routledge, Nueva York.

Becattini, G., Bellandi, M. y De Propris, L. (eds.), 2009. A Handbook of Industrial Districts. Edward Elgar, Cheltenham. 
Bellas, C. J. Bochniarz, Z., Jermakowicz, W., Meller, M. y Toft, D., 1994. Foreign privatization in Poland. Center for Social and Economic Research, Warsaw.

Brenner, R., 2003. The Boom and the Bubble: The US in the World Economy. Verso, Londres-Nueva York.

Brown, L. H., 1994. Telecommunications Equipment. Office of Industries, Washington.

Buesa, M. y Molero, J., 1988. Intervencionismo estatal y desarrollo industrial: las políticas industriales en la España de los años 80. Documento de trabajo 8816. Universidad Complutense de Madrid, Madrid.

Butcher, A., 1991. Global Competitiveness of U.S. Advanced-technology Manufacturing Industries: Communications Technology and Equipment, U.S. International Trade Commission, Washington.

Calvo, A., 2017ª . Multinacionales, Estado y empresa semipública en la industria de tecnología avanzada durante la década de 1980. Investigaciones de Historia Económica. 13 (1), 51-62.

Calvo, A., 2017b. Industrialización, desindustrialización y reindustrialización en España. Lecciones de la historia reciente. En seminario organizado por J. L. García Ruiz y Jesús M. ․ Valdaliso. Universidad Complutense de Madrid, Madrid.

Calvo, A., 2016. Historia de Telefónica: 1976-2000. Las telecomunicaciones en la España democrática. Ariel; Fundación Telefónica, Barcelona.

Calzada, J. y Costas, A., 2016. La liberalización de las telecomunicaciones en España: objetivos europeos versus intereses nacionales. Revista de Historia Industrial. 63 (25), 161-204.

Canalejo, M., 1995. Innovación organizativa en Alcatel Standard Eléctrica S. A. En: V Congreso Nacional de ACEDE, vol. 1. San Lorenzo de El Escorial, Madrid, pp. 205-216.

Canalejo, M., 2005. Una lección de cambio cultural: Alcatel. En: Uriz, J. (ed.). Homo valens: naturaleza, origen y gestión del valor en la empresa. Ediciones Díaz de Santos, Madrid, Buenos Aires, pp. 51-60.

Castells, M., 2002. Transformación del trabajo y el empleo y Estado de bienestar en la sociedad de la información. Gaceta Sindical, 2, junio, 25-42.

Chakravarthy, B., 1996. The Process of Transformation: In Search of Nirvana. European Management Journal, 14 (6), 529-539.

Cirillo, V., Guarascio, D. y Pianta, M., 2014. Will Europe's industry survive the crisis? Università degli Studi, Urbino.

Cluster Competitividad, 1998. Las telecomunicaciones en la Comunidad de Madrid: estrategias para la competitividad de la industria. Consejería de Economía y Empleo, Madrid.

Commission of the European Communities, 1983. Prospects for the development of new policies: Research and development, energy and new technologies. Office for Official Publications of the European Communities, Luxemburgo.

Commission of the European Communities, 1987. (COMC87) 2 0 final, Brussels, 30 June.

Commission of the European Communities, 1990. Green Paper on the Development of the Common Market for Telecom Equipment. Information Gatekeepers, Boston.

Commission of the European Communities, 1992. The European telecommunications equipment industry. The state of play, issues at stake and proposals for action. SEC, 92, 1049. Bruselas.

Crandall, R. W. y Flamm, K. (eds.), 1989. Changing the Rules: Technological Change, International Competition, and Regulation in Communications. Brookings Institution Press, Washington.

De la Fuente, J. M. y Galán, J. I., 2000. La gran empresa española: estrategia, propiedad y organización. Dirección y Organización, 23, 99-100.

De la Torre, J. 2017. Auge, quiebra y reconversión de la industria de electrodomésticos en España a la luz del Grupo Orbaiceta SA, c. 1950-1990. Investigaciones de Historia Económica, 13 (1), 26-37.

Díaz-Morlán, P. y Sáez-García, M., 2017. State aid for the restructuring of the Spanish steel industry from a European perspective (1975-1988). Investigaciones de Historia Económica, 13 (1), 38-50.

Díaz-Morlán, P. y Sáez-García, M. 2017a. Lecciones de la historia reciente de la siderurgia española. En: XII Congreso de la AEHE, sesión coordinada por J. L. García Ruiz y J. M. a Valdaliso. Salamanca, 20 y 21 de abril.

Díaz-Morlán, P. 2009. The restructuring of the Spanish integrated steel industry in the European panorama (1971-86): a lost opportunity. Business History, $51,547-568$

Díaz-Morlán, P., Escudero, A. y Sáez, M. Á. 2008. El desmantelamiento de la siderurgia integral del Mediterráneo español (1977-1984). Revista de Historia Industrial, 17 (38), 161-188.

Dörrenbächer, Ch., 2000. Between global market constraints and national dependencies: the internationalization of the world's leading telecommunications equipment suppliers. Transnational Corporations. 9 (3). UNCTAD.

Doz, Y., 1979. Government Control and Multinational Strategic Management: Power Systems and Telecommunications Equipment. Praeger, Nueva York.
EOI (coord.), 1999. Primer informe de prospectiva tecnológica industrial 1999. Ministerio de Industria y Energía, Madrid.

Espina, Á. 1995. Hacia una estrategia española de competitividad. Fundación Argentaria, Madrid.

European Commission, 1991. Concentration, telecommunication equipment, 1991. Official Journal, 233, 6-9-1991.

European Commission, 1997. 1996 Single Market Review. Office for Official Publications of the European Communities, Luxemburgo.

European Communities, 1992. Panorama of EC Industry Statistical Supplement 1992. Office for Official Publications of the European Communities, Luxemburgo.

EurWORK, 2003. Les systèmes de gouvernement d'entreprise et la nature de la restructuration industrielle. Observatory EurWORK, 10-2-2003.

Feldstein, M., 2007. American Economic Policy in the 1980s. University of Chicago Press, Chicago.

Fernández de Pinedo, E., 2003. Desarrollo, crisis y reconversión de la siderurgia española a través de una empresa vizcaína, AHV (1929-1996). Ekonomiaz, $54,28-51$.

Fitzgerald, R., 2015. The Rise of the Global Company: Multinationals and the Making of the Modern World. Cambridge University Press, Cambridge MA.

Forester, Tom, 1987. High-tech Society: The Story of the Information Technology Revolution. MIT Press, Cambridge MA.

Funk, J., 2002. Global Competition Between and Within Standards: The Case of Mobile Phones. Palgrave, Houndsmille.

Gazier, B. y Bruggeman, F. (eds.), 2008. Restructuring Work and Employment in Europe: Managing Change in an Era of Globalisation. Edward Elgar, Cheltenham.

Grindley, P. C., 1987. System X: The Failure of Procurement. Working Paper Series, no. 29, London Business School, London.

Hendry, J. y Eccles, T., 2005. European Cases in Strategic Management. Thomson Learning, Stamford CT.

Johnson, Ch., 1984. The Industrial Policy Debate. ICS Press, San Francisco CA.

Kaldor, M. Selchow, S. y Murray-Leach, T. (eds.), 2015. Subterranean Politics in Europe. Macmillan, Nueva York.

Kornelakis, A., 2015. European market integration and the political economy of corporate adjustment: OTE and Telecom Italia, 1949-2009. Business History, 57 (6), 885-902.

Laffitte, P. y Trégouët, R., 2001. Les conséquences de l'évolution scientifique et technique dans le secteur des télécommunications, Rapport no 159, 20-122001. Sénat, Paris.

Loos, F. y Larcher, G., 2007. Rapport d'étape du groupe de travail sur les perspectives du secteur des télécommunications en France et en Europe, 16-42007.

Mansell, R., Holmes, P. y Morgan, K., 1990. European Integration and Telecommunications: Restructuring Markets and Institutions. Prometheus. 8 (1), 51-66.

Michalet, C. A., 1981. Une nouvelle approche de la spécialisation internationale. Revue d'Économie Industrielle. 17, 61-75.

Ministerio de Industria y Energía, 1983. Libro blanco de la reindustrialización. Ministerio de Industria y Energía, Madrid.

Ministerio de Industria y Energía, 1984. Informe anual sobre la industria española. Ministerio de Industria y Energía, Madrid.

Ministerio de Industria y Energía, 1987. Informe sobre la industria española. Ministerio de Industria y Energía, Madrid.

Ministerio de Industria y Energía, 1997. Informe sobre industria 1996-1997. Servicio de Publicaciones, Servicio de Publicaciones, Madrid.

Monopolies and Mergers Commission, 1994. Alcatel Cable SA and STC Limited: a report on the proposed acquisition by Alcatel Cable SA of STC Limited; presented to Parliament, February 1. HMSO, Londres.

Navarro, M. 2005. La larga marcha de la siderurgia española hacia la competitividad. Economía Industrial, 355-356, 167-184.

Navarro, M., 1989. Crisis y reconversión de la siderurgia española, 1978-1988. Junta del Puerto de Pasajes y Ministerio de Obras Públicas y Urbanismo, Pasajes.

Neu, W. Neumann, K. H. y Schnöring, T., 1987. Trade patterns, industry structure and industrial policy in telecommunications. Telecommunications Policy, 11 (1), 31-44.

Noam, E., 1992. Telecommunications in Europe. Oxford University Press, Nueva York.

Observatorio Industrial de Electrónica, Tecnologías de la Información y Telecomunicaciones, 2008. Las políticas sectoriales y su repercusión en la reorganización del sector eTIC. Comisiones Obreras, Madrid.

O'Keefe, T. A., 1996. Latin American Trade Agreements. Transnational Publishers, Nueva York

Olley, G. S. y Pakes, A., 1996. The Dynamics of Productivity in the Telecommunications Equipment Industry. Econometrica, 64 (6), 1263-1297. 
Owen, G., 2012. Industrial policy in Europe since the Second World War: what has been learnt? ECIPE Occasional paper, 1. The European Centre for International Political Economy, Bruselas.

Patrick, H., 1986. Japanese high technology industrial policy in comparative context. Center on Japanese Economy and Business, Columbia University, Nueva York.

Quatrepoint, J. M., 1986. Les enjeux internationaux de la privatisation de la CGCT. Le Monde diplomatique, 8-12-1986.

Quatrepoint, J. M., 2015. Alstom, scandale d'État. Fayard, París.

Rojo, L. Á., 2002. La economía española en la democracia (1976-2000). En: Comín, F. et al. (eds.). Historia económica de España, siglos X-xx. Crítica, Barcelona, pp. 397-436.

Ruigrok, W. y Van Tulder, R., 1995. The Logic of International Restructuring: The Management of Dependencies in Rival Industrial Complexes. Routledge, Londres.

Sagardoy, J. A., 1984. Un acuerdo empresarial frente a la crisis: el acuerdo sobre salarios y empleo de ERT. Revista de Política Social, 142, 33-77.

Schipke, A. y Taylor, M., 2012. The Economics of Transformation: Theory and Practice in the New Market Economies. Springer, Londres.

Schmoch U. y Schnöring, T., 1994. Technological strategies of telecommunications equipment manufacturers: A patent analysis. Telecommunications Policy, 18 (5), 397-413.

Smidt, M. de y Weber, E., 2013. The Corporate Firm in a Changing World Economy: Case Studies in the Geography of Enterprise. Routledge, Londres-Nueva York.
Stone, N., 1989. The Globalization of Europe: an Interview with Wisse Dekker Harvard Business Review, 3, 90-95.

Sutton, J., 2001. Technology and Market Structure: Theory and History MIT Press Cambridge.

Thatcher, M., 1999. The Politics of Telecommunications: National Institutions. Oxford University Press, Oxford.

Trappman, V., 2013. Fallen heroes in global capitalism: Workers and the Restructuring of the Polish Steel Industry. MacMillan, Nueva York.

United States Congress, 1990. Telecommunications Opportunities in Eastern Europe: Hearing Before the Subcommittee on Telecommunications and Finance of the Committee on Energy and Commerce, vol. 4, U.S. Government Printing Office, Washington.

Valdaliso, J. M., 2003. Crisis y reconversión de la industria de construcción naval en el País Vasco. Ekonomiaz: Revista Vasca de Economía. 54, 52-67.

Viaña, E., 1991. Políticas industriales en sectores maduros. El caso de la siderurgia integral española (1980-1983). Universidad Complutense de Madrid Madrid.

Weiss, S. E., 1993. Analysis of Complex Negotiations in International Business: The RBC Perspective. Organization Science. 4 (2), 269-300.

Yue, W. y Chung-SokSuh, 2009. Towards a re-conceptualization of firm internationalization: Heterogeneous process, subsidiary roles and knowledge flow. Journal of International Management, 15 (4), 447-459. 